\title{
Survivin Selectively Modulates Genes Deregulated in Human Leukemia Stem Cells
}

\author{
Seiji Fukuda, ${ }^{1,2}$ Mariko Abe, ${ }^{1}$ Chie Onishi, ${ }^{3}$ Takeshi Taketani, ${ }^{1,4}$ Jamiyan Purevsuren, ${ }^{1}$ \\ Seiji Yamaguchi, ${ }^{1}$ Edward M. Conway, ${ }^{5}$ and Louis M. Pelus ${ }^{2}$
}

${ }^{1}$ Department of Pediatrics, Shimane University School of Medicine, 89-1 Enya-Cho, Izumo, Shimane 693-8501, Japan

${ }^{2}$ Department of Microbiology and Immunology, Indiana University School of Medicine, Indianapolis, IN 46202-5254, USA

${ }^{3}$ Department of Hematology, Shimane University School of Medicine, Shimane 693-8501, Japan

${ }^{4}$ Division of Blood Transfusion, Shimane University Hospital, Shimane 693-8501, Japan

${ }^{5}$ Centre for Blood Research, University of British Columbia, Vancouver, BC, Canada V6T 1Z3

Correspondence should be addressed to Seiji Fukuda, sfukuda@med.shimane-u.ac.jp

Received 1 September 2010; Accepted 19 October 2010

Academic Editor: Shih Hwa Chiou

Copyright (C) 2011 Seiji Fukuda et al. This is an open access article distributed under the Creative Commons Attribution License, which permits unrestricted use, distribution, and reproduction in any medium, provided the original work is properly cited.

\begin{abstract}
ITD-Flt3 mutations are detected in leukemia stem cells (LSCs) in acute myeloid leukemia (AML) patients. While antagonizing Survivin normalizes ITD-Flt3-induced acute leukemia, it also impairs hematopoietic stem cell (HSC) function, indicating that identification of differences in signaling pathways downstream of Survivin between LSC and HSC are crucial to develop selective Survivin-based therapeutic strategies for AML. Using a Survivin-deletion model, we identified 1,096 genes regulated by Survivin in ITD-Flt3-transformed c-kit ${ }^{+}$, Sca-1 ${ }^{+}$, and lineage ${ }^{\text {neg }}$ (KSL) cells, of which 137 are deregulated in human LSC. Of the 137, 124 genes were regulated by Survivin exclusively in ITD-Flt $3^{+}$KSL cells but not in normal CD $34^{\text {neg }}$ KSL cells. Survivin-regulated genes in LSC connect through a network associated with the epidermal growth factor receptor signaling pathway and falls into various functional categories independent of effects on apoptosis. Pathways downstream of Survivin in LSC that are distinct from HSC can be potentially targeted for selective anti-LSC therapy.
\end{abstract}

\section{Introduction}

Survivin has been implicated in regulation of apoptosis, cell division, and cell cycle both in cancer cells and normal tissues, through caspase-dependent and -independent mechanisms [1-3]. We previously showed that Survivin is expressed and growth factor regulated in human $\mathrm{CD} 34^{+}$cells [4-6]. Antagonizing Survivin impairs production of mouse bone marrow hematopoietic progenitor cells in vitro $[4,7]$ and conditional Survivin gene deletion in vivo in mice leads to bone marrow ablation as a result of loss of hematopoietic stem and progenitor cells (HSPC) [8]. In contrast to tight regulation of Survivin by hematopoietic growth factors in normal $\mathrm{CD}_{3} 4^{+}$cells, deregulated expression of Survivin is frequently observed in hematological diseases, particularly those associated with hematopoietic stem cell (HSC) expansion. For instance, Survivin is aberrantly overexpressed in acute myeloid leukemia $[9,10]$ but downregulated in marrow cells of patients with aplastic anemia where HSPC are significantly reduced [11]. These findings suggest that Survivin regulates HSPC fate under normal and pathological conditions.

We previously reported that ITD-Flt3 mutations found in $\sim 25-30 \%$ of patients with acute myeloid leukemia (AML) and strongly associated with poor prognosis [12-14], increase expression of Survivin. Survivin mediates aberrant hematopoietic cell proliferation induced by ITD-Flt3 and regulates development of ITD-Flt3 ${ }^{+}$acute leukemia, suggesting that antagonizing Survivin may provide therapeutic benefit for patients with AML expressing ITD-Flt3 [14]. Survivin is the fourth most highly expressed transcript in cancer [15] and is commonly associated with a higher proliferative index, reduced apoptosis, resistance to chemotherapy and increased rate of tumor recurrence in cancer cells, making anti-Survivin therapy an attractive strategy in cancer [3]. Several anti-Survivin preclinical trials in solid tumor models 
show that disrupting Survivin can reduce tumor growth [1$3]$. However, studies from our group and others indicate that Survivin regulates normal $\operatorname{HSPC}[4,7,8]$, suggesting that targeting Survivin will likely result in hematopoietic toxicity. Therefore, identification of differences in signaling cascades downstream of Survivin between normal HSPC and cancer stem cells (CSC) or leukemia stem cells (LSC) are required to pinpoint targets that can effectively eradicate CSC/LSC with little toxicity on HSC. Previous reports show that ITD-Flt3 mutations are present in human LSC [13] and genes expressed in AML stem cells are deregulated [16]. The primary purpose of this study was to identify downstream Survivin signaling pathways in LSC that are distinct from normal HSC. Using ITD-Flt3 transformed c$\mathrm{kit}^{+}, \mathrm{Sca}-1^{+}$, and lineage ${ }^{\text {neg }}$ (KSL) cells from conditional Survivin knockout mice as surrogates for AML stem cells and littermate controls, we identified a panel of genes that are specifically regulated by Survivin in ITD-Flt3 transformed KSL cells and known to be deregulated in human LSC. The data identify selective signaling pathways downstream of Survivin in LSC that are distinct from normal HSC that can be potentially targeted for selective anti-LSC therapy.

\section{Materials and Methods}

2.1. Antibodies and Cytokines. Anti-Fcy-III/II receptor antibody, APC conjugated antimouse c-kit (clone 2B8), biotinconjugated anti-Sca-1 (E13-161.7), R-Phycoerythrin (PE) conjugated anti-mouse CD3 (clone 143-2C11), GR-1 (clone RB6-8C5), B220 (clone RA3-6B2), Mac1 (clone M1/70), Ter119 (clone Ter119), rat IgG2a, rat IgG2b, hamster IgG, and Streptavidin-PE-Cy7 were purchased from BD Biosciences (San Diego, CA). Recombinant human Flt3 ligand (FL) and Thrombopoietin (Tpo) were provided by Amgen, Thousand Oaks, CA. Recombinant murine stem cell factor (rmSCF) was purchased from R\&D Systems (Minneapolis, $\mathrm{MN})$. Tamoxifen and 4-hydroxy $(4 \mathrm{OH})$ tamoxifen were from Sigma-Aldrich (St. Louis, MO).

2.2. Cell Culture, Plasmid Transfection, Retrovirus Transduction, and In Vitro Survivin Gene Deletion. Mice with the Survivin gene flanked by loxP sites and a Tamoxifeninducible form of Cre (Cre-ER) were reported previously [14]. All mice were housed in microisolators with continuous access to rodent chow and acidified water. The Indiana University School of Medicine IACUC approved all experimental procedures. Retrovirus transduction of ITD-Flt3 into mouse bone marrow cells was carried out as described [14]. Briefly, bone marrow cells from littermate control Survivin ${ }^{\text {flox/flox }}$ or CreER-Survivin ${ }^{\text {flox/flox }}$ mice were transduced with ITD-Flt3 (N51) in MSCV-IRES-EGFP vector [17]. Seventy-two hours after sequential transduction, the medium was replaced with IMDM containing 10\% FBS and the cells were incubated for 14 days without growth factors in the presence of $1 \mathrm{uM}$ of $4 \mathrm{OH}$-Tamoxifen to induce Survivin gene deletion. All cells were cultured in triplicates in two independent experiments. Viable cells were enumerated using trypan blue exclusion and $\mathrm{GFP}^{+}, \mathrm{c}-\mathrm{kit}^{+}, \mathrm{Sca}-1^{+}$, and lineage negative (KSL) cells were sorted on day 14 by FACSAria (BD Biosciences). Sorted cells were immediately lysed and subjected to differential mRNA microarray analysis.

2.3. In Vivo Survivin Deletion. Survivin ${ }^{\text {flox/flox }}$ and CreERSurvivinflox/flox mice were treated with $5 \mathrm{mg}$ Tamoxifen ( $5 \mathrm{mg} / \mathrm{mouse}$ i.p.) for 3 consecutive days and allowed to rest for 3 days, and Tamoxifen was administered for 3 additional days. Fourteen days after the final Tamoxifen injection, marrow cells were harvested, stained with anti-CD34, c-kit, Sca-1, and lineage markers and CD $34^{\text {neg }}$ KSL cells isolated by FACSAria for mRNA microarray analysis.

2.4. $m R N A$ Microarray. Sorted cells were immediately lysed and subjected to differential mRNA microarray analysis. Microarray analysis was performed on a fee basis by Miltenyi Biotec (Auburn, CA). Briefly, 250 nanograms of each cDNA were used as template for $\mathrm{Cy} 3$ and $\mathrm{Cy} 5$ labeling which was performed according to Miltenyi Biotec's proprietary protocol. Equal amounts of labeled cDNAs from Tamoxifentreated Survivin flox/flox and CreER-Survivin flox/flox mice or those cells expressing ITD-Flt3 were hybridized overnight ( 17 hours, $65^{\circ} \mathrm{C}$ ) to Agilent Whole Mouse Genome Oligo Microarrays $(44 \mathrm{~K})$ according to the manufacturers' protocol. Fluorescence signals of the hybridized microarrays were detected using Agilent's DNA microarray scanner (Agilent, Palo Alto, USA). The Agilent Feature Extraction Software (FES) was used to read out and process the microarray image files. The software determines feature intensities and ratios (including background subtraction and normalization), rejects outliers, and calculates statistical confidences ( $P$-values). For determination of differential gene expression, FES derived output data files were further analyzed using the Rosetta Resolverâ gene expression data analysis system (Rosetta Biosoftware, Seattle, USA). Significantly regulated genes were annotated and assigned to functional categories using the DAVID 2008 (the Database for Annotation, Visualization and Integrated Discovery; http://david.abcc.ncifcrf.gov/home.jsp) program [18]. Functional networks of the genes regulated by Survivin was visualized using Cytoscape software: http://www.cytoscape.org/ [19].

\section{Results}

3.1. Reduction in Proliferation ITD-Flt3 Transformed KSL Cells by Survivin Deletion Is Associated with Alteration of Expression of 1,096 Genes Classified into Various Biological Functions. While incubation of marrow cells transduced with wild-type Flt3 in IMDM containing 10\% FBS without hematopoietic any growth factors failed to support KSL proliferation, overexpression of ITD-Flt3-EGFP in primary mouse bone marrow cells results in the ability of KSL cells to proliferate in the same culture condition without additional any hematopoietic growth factors as we reported, indicating that ITD-Flt3 is sufficient to transform primitive HSPC [14]. Incubation of ITD-Flt3 transduced marrow cells derived from CreER-Survivin ${ }^{\text {flox/flox }}$ mice with 1uM 4OH-Tamoxifen significantly reduced factor-independent KSL cells on day 14 compared to Survivin ${ }^{\text {flox/flox }}$ cells treated in exactly the same 

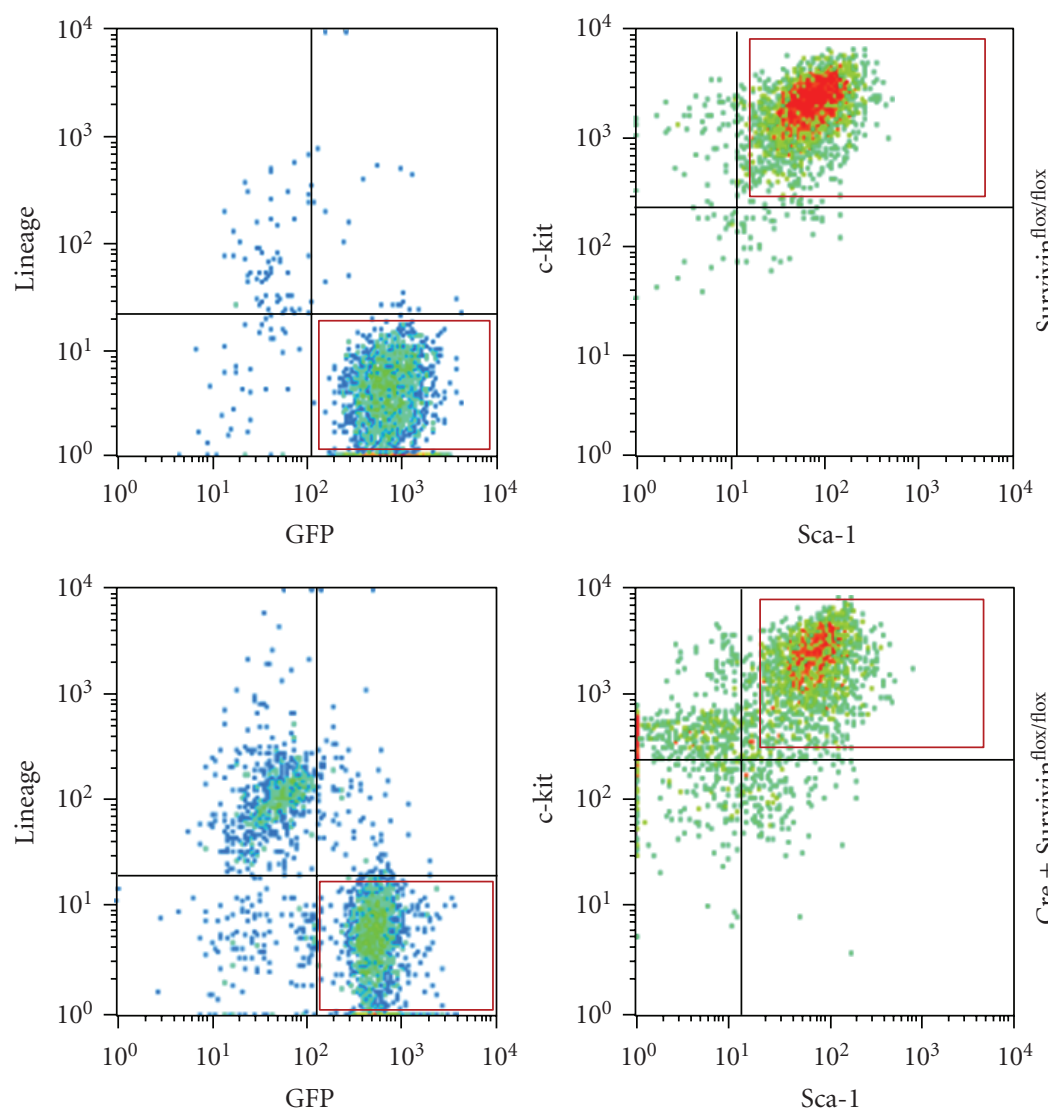

(a)

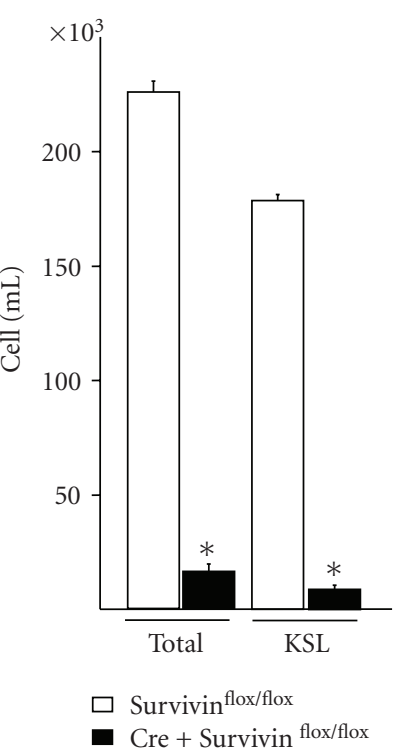

(b)

FIgUre 1: The effect of Survivin deletion on the number of KSL cells transformed by ITD-Flt3 (a) The KSL cells transformed by ITD-Flt3 were FACS sorted using GFP as a marker. Marrow cells derived from littermate control Survivin ${ }^{\text {flox/flox }}$ or CreER-Survivin ${ }^{\text {flox/flox }}$ mice were transduced with ITD-Flt3 (N51) in MSCV-IRES-EGFP vector. Seventy-two hours after transduction, the medium was replaced with IMDM containing $10 \% \mathrm{FBS}$ and the cells were incubated for 14 days in the presence of $1 \mathrm{uM}$ of $4 \mathrm{OH}$-Tamoxifen without hematopoietic growth

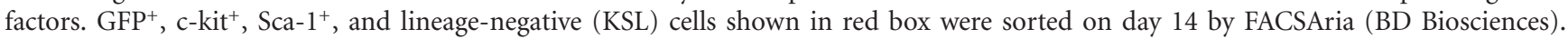
(b) The number of whole cells and KSL cells derived from Survivin ${ }^{\text {flox/flox }}$ or CreER-Survivin ${ }^{\text {flox/flox }}$ marrow cells transduced with ITD-Flt3 cultured with $4 \mathrm{OH}$-tamoxifen in the absence of any growth factors was quantitiated in triplicate wells of each sample averaged from 2 independent experiments. ${ }^{*} P<.02$ compared to control Survivin ${ }^{\text {flox/flox }}$.

manner (Figure 1), confirming that Survivin is required for factor independent growth of ITD-Flt3 transformed KSL cells.

To investigate the mechanism by which Survivin regulates aberrant proliferation of ITD-Flt3 transformed KSL cells, mRNA expression was compared between ITD-Flt3 transformed Survivin ${ }^{\text {flox/flox }}$ and CreER-Survivin ${ }^{\text {flox/flox }}$ KSL using mRNA microarrays. Although inhibition of Survivin mRNA expression in CreER-Survivin ${ }^{\text {flox/flox }}$ KSL cells by $4 \mathrm{OH}$-Tamoxifen was only $50 \%$ compared to control, the mRNA microarray identified 1,096 transcripts differentially regulated by Survivin. These genes were classified based on biological process and molecular function defined by Gene Ontology Term (http://www.geneontology.org/) using DAVID 2008 program (Figure 2). Representative groups for biological process include phosphate metabolic process, cell cycle, cell division, response to DNA damage stimulus, RNA biosynthetic process and transcription (Figure $2(\mathrm{a}), P<$ $.02)$. Ion-binding, nucleotide-binding, DNA-binding, and protein kinase activity were the top 4 significantly enriched categories in molecular function defined by Gene Ontology database (Figure 2(b), $P<.02$ ). The list of genes classified by biological process and molecular function are listed in supplementary Table S1 available at doi:10.1155/2011/946936.

3.2. Survivin Modulates Expression of Genes Deregulated in Human AML LSC. The requirement of Survivin for the selfrenewing capability of ITD-Flt3 transformed KSL cells or CFU [14] and the presence of ITD-Flt3 in LSC [13] strongly suggests that Survivin is important for LSC fate decisions resulting from deregulated gene expression. We compared 1,096 differentially expressed genes in Survivin deleted ITDFlt $3{ }^{+} \mathrm{KSL}$ cells with the existing deregulated gene expression database for human AML stem cells [16]. Out of 1,096 genes regulated by Survivin in KSL cells transformed by ITD-Flt3, 137 genes are also listed in the deregulated molecules in human AML stem cells (Tables 1(a)-1(d)) [16]. The relationship between Survivin and LSC on the modulation 


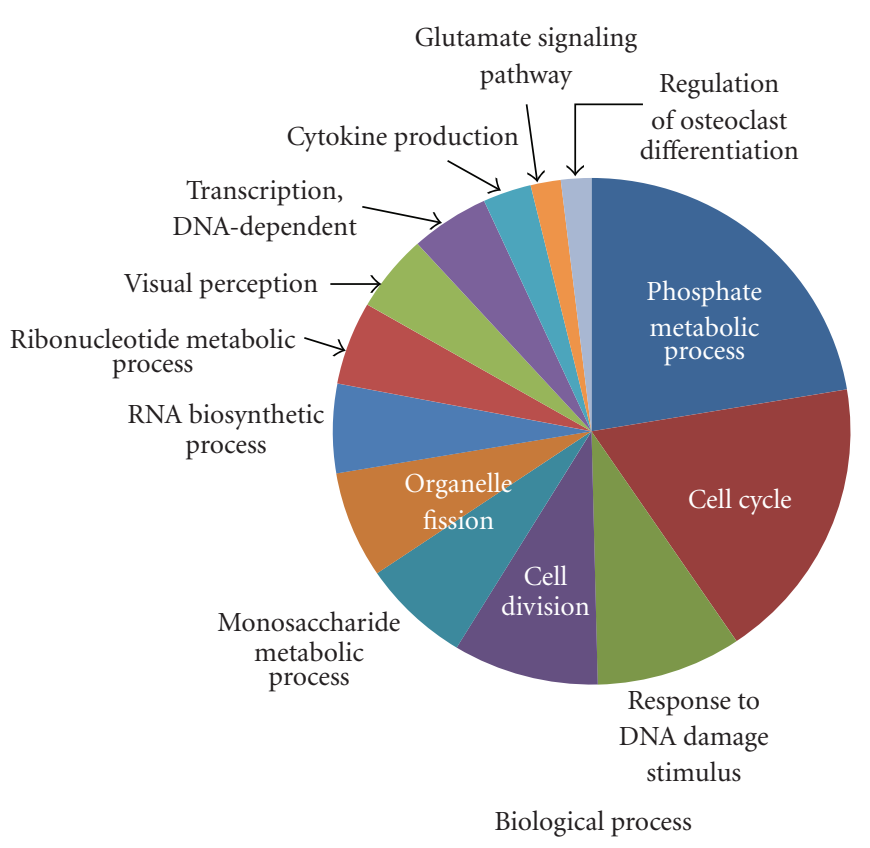

(a)

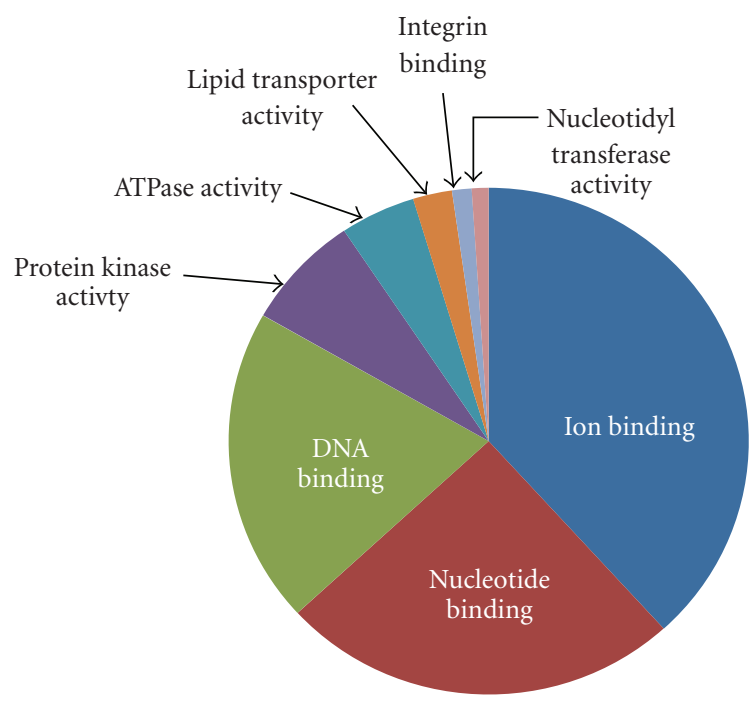

Molecular function

(b)

FIGURE 2: Classification of the Survivin regulated genes in ITD-Flt3 transformed KSL cells. The 1,096 genes identified by Survivin gene deletion were classified into biological process (a) and molecular function (b) defined by Gene Ontology (GO) Term using DAVID program $(P<.02)$. Genes for which annotations could not be assigned were excluded. Representative functional categories are shown in the figures because of redundancies in classification categories. The complete Gene ID and annotations are listed in Supplementary Table S1 available at doi:10.1155/2011/946936.

of the gene expression is illustrated in Figure 3(a). Of the 137 genes identified, 79 genes were downregulated by Survivin deletion while 58 genes were upregulated, implying that these genes are conversely increased and decreased by the presence of Survivin in LSC (Figure 3(a)). In contrast, 92 genes were upregulated and 45 genes were downregulated by LSC. Among the 79 genes downregulated genes by Survivin deletion, 55 transcripts were upregulated (Figure 3(a) and Table 1(a)) whereas 24 genes were downregulated by LSC (Figure 3(a) and Table 1(c)). Similarly, out of 58 upregulated transcripts by Survivin deletion, 21 genes were downregulated (Figure 3(a) and Table 1(b)) and 37 genes were upregulated in LSC (Figure 3(a) and Table 1(d)) (Figure 3(a)).

Next, we classified the 137 genes into functional annotation groups using the DAVID program $(P<.05$, Figure 3(b)). Significantly enriched functional groups were annotated as phosphoprotein, nucleus, acetylation, cell cycle, ATP binding, regulation of EGF signaling pathway, cell adhesion and others. The size of each circle in Figure 3(b) represents the number of genes involved in each functional category and the thickness of the line indicates the number of genes shared with any function, suggesting enrichment of the gene groups with functional redundancy. Among the molecules most frequently shared within the functional groups include BGLAP, Chrac1, Hmgb1 and Smarce1. Similarly, 76 genes upregulated or downregulated both by Survivin and LSC $(55+21$ genes shown in Figure 1(a)) were functionally classified (Figure 3(c)). Phosphoprotein, acetylation, DNA binding, ATP binding and DNA replication were significantly enriched.

The 1,096 differentially Survivin-regulated genes were also searched against the list of genes expressed in mouse HSC [20]. We identified 94 differentially expressed genes in the list of genes that include HSC. There were 45 genes whose expression was selectively enriched in HSC compared to other populations (Table 2). Crem, Emp1, Hmga2, Lrrn1, Maff, Myef2, Rps4x, and Sos1 listed in HSC database are also deregulated in LSC. We next compared the human LSC associated 137 genes regulated by Survivin in ITDFlt $3{ }^{+} \mathrm{KSL}$ cells with differentially regulated genes in normal bone marrow $\mathrm{CD} 34^{\text {neg }}$ KSL cells obtained from CreERSurvivin ${ }^{\text {flox/flox }}$ and control Survivin ${ }^{\text {flox/flox }}$ mice following Survivin deletion. Tamoxifen reduced Survivin expression by 10 -fold in CD $34^{\text {neg }}$ KSL cells from CreER-Survivin ${ }^{\text {flox/flox }}$ mice compared to control Survivin ${ }^{\text {flox/flox }}$ in two independent experiments. Out of 137 genes, Arg2, Med25, Pmaip1, Pola2, Ube3b, Ephb2 and Rab18 were differentially regulated in both ITD-Flt $3{ }^{+} \mathrm{KSL}$ cells and normal CD $34^{\text {neg }}$ KLS cells by Survivin deletion. In contrast, Cenpa, Cpd, Myef2, Nmt2, Taflb and Tmpo were downregulated in ITD-Flt $3^{+}$KSL cells while they were upregulated in normal CD34 ${ }^{\text {neg }}$ KSL cells by Survivin deletion. These findings suggest that the 124 genes are regulated by Survivin exclusively in ITD-Flt $3{ }^{+}$KSL cells but not in CD34 $4^{\text {neg }} \mathrm{KSL}$ cells. The complete list of the genes regulated by Survivin in CD34 $4^{\text {neg }}$ KSL cells will be reported elsewhere (manuscript in preparation). 
TABLE 1

(a) Genes upregulated in LSC but downregulated in ITD-Flt $3{ }^{+}$KSL cells deleted with Survivin (55 genes).

\begin{tabular}{|c|c|c|}
\hline Symbol & Name & Fold change \\
\hline Acaa2 & $\begin{array}{l}\text { acetyl-Coenzyme A acyltransferase } 2 \text { (mitochondrial 3-oxoacyl-Coenzyme A thiolase) (Acaa2), } \\
\text { [NM_177470] }\end{array}$ & -3.7 \\
\hline Ankrd12 & $\begin{array}{l}\text { Mus musculus } 15 \text { days embryo head cDNA, RIKEN full-length enriched library, } \\
\text { clone:D930020E11 product: unknown EST, full insert sequence. [AK086311] }\end{array}$ & -5.5 \\
\hline Ankrd28 & $\begin{array}{l}\text { Mus musculus } 2 \text { days neonate thymus thymic cells cDNA, RIKEN full-length enriched library, } \\
\text { clone:E430019N21 product: unknown EST, full insert sequence. [AK088541] }\end{array}$ & -2.9 \\
\hline Ap1g2 & adaptor protein complex AP-1, gamma 2 subunit (Ap1g2), [NM_007455] & -5.2 \\
\hline Arhgef18 & rho/rac guanine nucleotide exchange factor (GEF) 18 (Arhgef18), [NM_133962] & -3.6 \\
\hline Arrdc1 & arrestin domain containing 1 (Arrdc1), [NM_178408] & -2.1 \\
\hline Atp11a & ATPase, class VI, type 11A, [AK006628] & -2.6 \\
\hline BGLAP & bone gamma carboxyglutamate protein 1 (Bglap1), [NM_007541] & -10.2 \\
\hline Cars & cysteinyl-tRNA synthetase (Cars), [NM_013742] & -2.3 \\
\hline Ccr1 & chemokine (C-C motif) receptor 1 (Ccr1), [NM_009912] & -3.5 \\
\hline Cd96 & CD96 antigen (Cd96), [NM_032465] & -2.1 \\
\hline Cfp & complement factor properdin (Cfp), [NM_008823] & -4.3 \\
\hline Cyyr 1 & cysteine and tyrosine-rich protein 1 (Cyyr1), [NM_144853] & -2.7 \\
\hline Dpagt1 & $\begin{array}{l}\text { dolichyl-phosphate (UDP-N-acetylglucosamine) acetylglucosaminephosphotransferase } 1 \\
\text { (GlcNAc-1-P transferase) (Dpagt1), [NM_007875] }\end{array}$ & -2.8 \\
\hline Dpp9 & dipeptidylpeptidase 9 (Dpp9), [NM_172624] & -2.4 \\
\hline Elovl1 & $\begin{array}{l}\text { elongation of very long chain fatty acids (FEN1/Elo2, SUR4/Elo3, yeast)-like } 1 \text { (Elovl1), } \\
\text { [NM_019422] }\end{array}$ & -2.5 \\
\hline Ets2 & E26 avian leukemia oncogene 2, 3' domain (Ets2), [NM_011809] & -2.5 \\
\hline Fgr & $\begin{array}{l}\text { Mus musculus Gardner-Rasheed feline sarcoma viral (Fgr) oncogene homolog (Fgr), mRNA } \\
\text { [NM_010208] }\end{array}$ & -2.9 \\
\hline Gfil & growth factor independent 1 (Gfil), [NM_010278] & -2.7 \\
\hline Gga2 & golgi associated, gamma adaptin ear containing, ARF binding protein 2 (Gga2), [NM_028758] & -2.5 \\
\hline Git2 & G protein-coupled receptor kinase-interactor 2, [AK017943] & -3.1 \\
\hline Hdac10 & histone deacetylase 10 (Hdac10), [NM_199198] & -4.1 \\
\hline Ipo13 & importin 13 (Ipo13), [NM_146152] & -2.3 \\
\hline Isynal & myo-inositol 1-phosphate synthase A1 (Isyna1), [NM_023627] & -2.5 \\
\hline Klhl17 & kelch-like 17 (Drosophila) (Klhl17), [NM_198305] & -4.8 \\
\hline Lars2 & $\begin{array}{l}\text { leucyl-tRNA synthetase, mitochondrial (Lars2), nuclear gene encoding mitochondrial protein, } \\
\text { [NM_153168] }\end{array}$ & -3.6 \\
\hline Lrrk1 & leucine-rich repeat kinase 1 (Lrrk1), [NM_146191] & -2.7 \\
\hline Lztr1 & leucine-zipper-like transcriptional regulator, 1 (Lztr1), [NM_025808] & -3.4 \\
\hline Mapk8ip3 & mitogen-activated protein kinase 8 interacting protein 3 (Mapk8ip3), [NM_013931] & -2.9 \\
\hline Mcm8 & minichromosome maintenance deficient 8 (S. cerevisiae) (Mcm8), [NM_025676] & -2.4 \\
\hline Med25 & TCBAP0758 protein (Fragment) homolog [Homo sapiens], [AK165760] & -5.4 \\
\hline
\end{tabular}


(a) Continued.

\begin{tabular}{|c|c|c|}
\hline Symbol & Name & Fold change \\
\hline Mr1 & laminin receptor 1 (ribosomal protein SA) (Lamr1), [NM_011029] & -2.6 \\
\hline Napa & N-ethylmaleimide sensitive fusion protein attachment protein alpha (Napa), [NM_025898] & -3.0 \\
\hline Ndrg1 & N-myc downstream regulated gene 1 (Ndrg1), [NM_010884] & -3.3 \\
\hline Nsfl1c & NSFL1 (p97) cofactor (p47) (Nsfl1c), [NM_198326] & -2.2 \\
\hline Otud5 & $\begin{array}{l}\text { bZ30I22.1 (Novel protein similar to human FLJ12550) (Fragment) homolog [Brachydanio rerio], } \\
\text { [AK169921] }\end{array}$ & -3.1 \\
\hline Pank4 & pantothenate kinase 4 (Pank4), [NM_172990] & -3.0 \\
\hline Pgls & 6-phosphogluconolactonase, [AK158308] & -5.6 \\
\hline Phkg2 & phosphorylase kinase, gamma 2 (testis) (Phkg2), [NM_026888] & -3.3 \\
\hline Pmaip 1 & phorbol-12-myristate-13-acetate-induced protein 1 (Pmaip1), [NM_021451] & -6.6 \\
\hline Pola2 & polymerase (DNA directed), alpha 2 (Pola2), [NM_008893] & -2.7 \\
\hline Polg & polymerase (DNA directed), gamma 2, accessory subunit (Polg2), [NM_015810] & -3.2 \\
\hline Rnf126 & ring finger protein 126 (Rnf126), [NM_144528] & -2.1 \\
\hline Ropn1l & ropporin 1-like (Ropn1l), [NM_145852] & -6.8 \\
\hline Rtel1 & regulator of telomere elongation helicase 1 (Rtel1), [NM_001001882] & -4.3 \\
\hline Slc1a5 & solute carrier family 1 (neutral amino acid transporter), member 5 (Slc1a5), [NM_009201] & -2.3 \\
\hline Slc25a28 & solute carrier family 25, member 28 (Slc25a28), [NM_145156] & -2.9 \\
\hline Snapc4 & small nuclear RNA activating complex, polypeptide 4 (Snapc4), [NM_172339] & -2.7 \\
\hline Solh & small optic lobes homolog (Drosophila) (Solh), [NM_015830] & -3.9 \\
\hline Synj1 & PREDICTED: synaptojanin 1 (Synj1), [XM_358889] & -2.8 \\
\hline Trim 21 & tripartite motif protein 21 (Trim21), [NM_009277] & -11.4 \\
\hline Trpm2 & transient receptor potential cation channel, subfamily M, member 2 (Trpm2), [NM_138301] & -4.2 \\
\hline Trpm7 & transient receptor potential cation channel, subfamily M, member 7 (Trpm7), [NM_021450] & -3.2 \\
\hline Ube $3 b$ & ubiquitin protein ligase E3B (Ube3b), [NM_054093] & -2.8 \\
\hline Upp1 & uridine phosphorylase 1 (Upp1), [NM_009477] & -3.4 \\
\hline
\end{tabular}

Fold change: ITD-Flt $3^{+}$KLS cells derived from CreER-Survivin ${ }^{\mathrm{fx} / \mathrm{fx}}$ compared to control Survivin $^{\mathrm{fx} / \mathrm{fx}}$ in two experiments.

(b) Genes downregulated in LSC but upregulated in ITD-Flt ${ }^{+}$KSL cells deleted with Survivin (21 genes)

\begin{tabular}{lll}
\hline symbol & Name & Fold change \\
\hline Aebp2 & AE binding protein 2 (Aebp2), transcript variant 3, [NM_009637] & 11.4 \\
Anp32b & $\begin{array}{l}\text { unspliced dna for: PROLIFERATION RELATED ACIDIC LEUCINE RICH PROTEIN PAL31 } \\
\text { (SIMILAR TO ACIDIC PROTEIN RICH IN LEUCINES) homolog [Mus musculus], .. }\end{array}$ \\
App & amyloid beta protein precursor, [M18373] \\
Cd164 & CD164 antigen, [AK018009] \\
Crem & cAMP responsive element modulator. [AK016156] & 2.9 \\
\hline
\end{tabular}


(b) Continued.

\begin{tabular}{|c|c|c|}
\hline symbol & Name & Fold change \\
\hline Emp1 & epithelial membrane protein 1 (Emp1), [NM_010128] & 2.3 \\
\hline Fbxl17 & $\begin{array}{l}\text { Mus musculus } 10 \text { days neonate cerebellum cDNA, RIKEN full-length enriched library, } \\
\text { clone:B930094M09 product: unknown EST. [AK081162] }\end{array}$ & 5.1 \\
\hline Gas2l3 & $\begin{array}{l}\text { Mus musculus } 16 \text { days embryo head cDNA, RIKEN full-length enriched library, } \\
\text { clone:C130036O09 product: unclassifiable, [AK048137] }\end{array}$ & 12.5 \\
\hline Myef2 & myelin basic protein expression factor 2, repressor (Myef2), [NM_010852] & 10.6 \\
\hline Nrip1 & nuclear receptor interacting protein 1 (Nrip1), [NM_173440] & 6.2 \\
\hline Pla2g12a & phospholipase A2, group XIIA (Pla2g12a), [NM_023196] & 3.2 \\
\hline Psmd11 & $\begin{array}{l}\text { Mus musculus adult male testis cDNA, RIKEN full-length enriched library, clone: 1700089D09 } \\
\text { product: unclassifiable. [AK007029] }\end{array}$ & 12.3 \\
\hline Rps20 & $\begin{array}{l}\text { Mus musculus bone marrow macrophage cDNA, RIKEN full-length enriched library, } \\
\text { clone:I830013G23 product: hypothetical protein. [AK150667] }\end{array}$ & 5.5 \\
\hline Senp7 & SUMO1/sentrin specific protease 7 (Senp7), transcript variant 3, [NM_001003972] & 12.3 \\
\hline Slc25a16 & $\begin{array}{l}\text { solute carrier family } 25 \text { (mitochondrial carrier, Graves disease autoantigen), member } 16 \\
\text { (Slc25a16), [NM_175194] }\end{array}$ & 2.8 \\
\hline Spire1 & spire homolog 1 (Drosophila) (Spire1), transcript variant 2, [NM_176832] & 9.5 \\
\hline Tdrd3 & $\begin{array}{l}\text { Mus musculus adult male olfactory brain cDNA, RIKEN full-length enriched library, } \\
\text { clone:6430599B16 product: hypothetical Tudor domain containing protein. [AK078326] }\end{array}$ & 2.9 \\
\hline Tmpo & thymopoietin (Tmpo), [NM_011605] & 4.3 \\
\hline Trps1 & $\begin{array}{l}\text { Mus musculus adult male adrenal gland cDNA, RIKEN full-length enriched library, clone: } \\
7330401 \mathrm{C} 17 \text { product: expressed sequence AI115454, [AK078617] }\end{array}$ & 11.4 \\
\hline Ube2n & ubiquitin-conjugating enzyme E2N (Ube2n), [NM_080560] & 2.4 \\
\hline Wtap & $\begin{array}{l}\text { Mus musculus } 12 \text { days embryo embryonic body between diaphragm region and neck cDNA, } \\
\text { RIKEN full-length enriched library, clone: } 9430038 \text { B09 product: unclassifiable. [AK020459] }\end{array}$ & 14.2 \\
\hline
\end{tabular}

Fold change: ITD-Flt $3^{+}$KLS cells derived from CreER-Survivin ${ }^{\mathrm{fx} / \mathrm{fx}}$ compared to control Survivin $^{\mathrm{fx} / \mathrm{fx}}$ in two experiments.

(c) Genes down regulated in LSC and in ITD-Flt $3^{+}$KSL cells deleted with Survivin (24 genes)

\begin{tabular}{llc}
\hline Symbol & Name & Fold change \\
\hline Arg2 & arginase type II (Arg2), [NM_009705] & -2.2 \\
Atp2c1 & CALCIUM-TRANSPORTING ATPASE TYPE 2C, MEMBER 1 (EC 3.6.3.8) (ATPASE 2C1) & -2.2 \\
Chrac1 & chro-DEPENDENT CA2+ PUMP PMR1) homolog & -4.3 \\
Dhx30 & DEAH (Asp-Glu-Ala-His) box polypeptide 30 (Dhx30), [NM_133347] & -3.1 \\
Dsg2 & desmoglein 2, (cDNA clone IMAGE:4036406), [BC034056] & -4.1 \\
Eef1g & eukaryotic translation elongation factor 1 gamma (Eef1g), [NM_026007] & -2.2 \\
Herc5 & hypothetical regulator of chromosome condensation (RCC1) containing protei . . & -2.3 \\
Hmga2 & high mobility group AT-hook 2 (Hmga2), [NM_178057] & -5.0 \\
Hmgb1 & high mobility group box 1, [BC064790] & -3.4 \\
Hmmr & hyaluronan mediated motility receptor (RHAMM) (Hmmr), [NM_013552] & -3.2 \\
Il15 & interleukin 15 (Il15), [NM_008357] & -6.1 \\
Jmy & junction-mediating and regulatory protein (Jmy), [NM_021310] & -4.1 \\
Lrrn1 & $\begin{array}{l}\text { Mus musculus 10, 11 days embryo whole body cDNA, RIKEN full-length enriched library, } \\
\text { clone:2810047E21 product: unclassifiable, full insert sequence. [AK012914] }\end{array}$ & -4.0 \\
\hline
\end{tabular}


(c) Continued.

\begin{tabular}{|c|c|c|}
\hline Symbol & Name & Fold change \\
\hline Maff & $\begin{array}{l}\text { v-maf musculoaponeurotic fibrosarcoma oncogene family, protein F (avian) (Maff), } \\
\text { [NM_010755] }\end{array}$ & -8.4 \\
\hline Mapk14 & mitogen activated protein kinase 14 (Mapk14), [NM_011951] & -2.4 \\
\hline Ncoa7 & nuclear receptor coactivator 7, [BC076623] & -8.9 \\
\hline Nedd1 & neural precursor cell expressed, developmentally downregulated gene 1 (Nedd1), [NM_008682] & -2.6 \\
\hline Parp11 & poly (ADP-ribose) polymerase family, member 11 (Parp11), [NM_181402] & -2.5 \\
\hline Pawr & PRKC, apoptosis, WT1, regulator (Pawr), [NM_054056] & -2.8 \\
\hline Rps $4 \mathrm{x}$ & ribosomal protein S4, X-linked (Rps4x), [NM_009094] & -2.2 \\
\hline Smarce1 & SWI [AK042961] & -2.9 \\
\hline Tpbg & trophoblast glycoprotein, [AK050794] & -4.5 \\
\hline Vwf & Von Willebrand factor homolog (Vwf), [NM_011708] & -5.8 \\
\hline Zbtb20 & zinc finger and BTB domain containing 20 (Zbtb20), [NM_019778] & -3.1 \\
\hline
\end{tabular}

Fold change: ITD-Flt $3^{+}$KLS cells derived from CreER-Survivin ${ }^{\mathrm{fx} / \mathrm{fx}}$ compared to control Survivin ${ }^{\mathrm{fx} / \mathrm{fx}}$ in two experiments.

(d) Genes upregulated in LSC and in ITD-Flt $3^{+}$KSL cells deleted with Survivin (37 genes).

\begin{tabular}{llc}
\hline symbol & Name & fold change \\
\hline Cenpa & $\begin{array}{l}\text { Mus musculus 0 day neonate eyeball cDNA, RIKEN full-length enriched library, } \\
\text { clone:E130306P06 product: hypothetical protein, [AK165029] }\end{array}$ & 10.7 \\
Clcn3 & chloride channel 3 (Clcn3), transcript variant c, [NM_173876] & 5.5 \\
Cpd & carboxypeptidase D (Cpd), [NM_007754] & 6.2 \\
Cul4b & cullin 4B,. [AK164640] & 4.9 \\
Ddx52 & DEAD (Asp-Glu-Ala-Asp) box polypeptide 52 (Ddx52), [NM_030096] & 3.3 \\
Dnajc1 & DnaJ (Hsp40) homolog, subfamily C, member 11 (Dnajc11), [NM_172704] & 6.4 \\
Ephb2 & Eph receptor B2 (Ephb2), [NM_010142] & 3.0 \\
Gnaq & guanine nucleotide binding protein, alpha q polypeptide (Gnaq), [NM_008139] & 17.2 \\
Gripap1 & premature mRNA for mKIAA1167 protein [AK173119] & 2.2 \\
Il1rap & interleukin 1 receptor accessory protein (Il1rap), transcript variant 2, [NM_134103] \\
Itsn2 & SH3 domain protein 1B, [AK161743] & 11.0 \\
Lass6 & longevity assurance homolog 6 (S. cerevisiae) (Lass6), [NM_172856] & 4.4 \\
Lpp & caseinolytic protease, ATP-dependent, proteolytic subunit homolog (E. coli) (Clpp), & 2.3 \\
Mppe1 & [NM_017393] & 2.1 \\
Mrps5 & metallophosphoesterase 1 (Mppe1), [NM_172630] & 3.3 \\
Myh9 & mitochondrial ribosomal protein S5, [AK047438] & 3.4 \\
Nck2 & myosin heavy chain IX (Myh9), [NM_181327] & 9.0 \\
Nin & non-catalytic region of tyrosine kinase adaptor protein 2 (Nck2), [NM_010879] & 2.8 \\
Nmt2 & microtubule associated serine/threonine kinase-like (Mastl), [NM_025979] & 4.8 \\
\hline
\end{tabular}


(d) Continued.

\begin{tabular}{llc}
\hline symbol & Name & Fold change \\
\hline Osbpl3 & $\begin{array}{l}\text { Mus musculus adult male aorta and vein cDNA, RIKEN full-length enriched library, } \\
\text { clone:A530055M08 product: unknown EST, [AK040984] }\end{array}$ & 8.7 \\
Paqr3 & $\begin{array}{l}\text { Mus musculus adult male pituitary gland cDNA, RIKEN full-length enriched library, } \\
\text { clone:5330440B03 product: unknown EST, [AK030634] }\end{array}$ & 4.4 \\
Pcbd2 & $\begin{array}{l}\text { pterin 4 alpha carbinolamine dehydratase/dimerization cofactor of hepatocyte nuclear factor 1 } \\
\text { alpha (TCF1) 2 (Pcbd2), [NM_028281] }\end{array}$ & 4.2 \\
Rab18 & RAB18, member RAS oncogene family (Rab18), [NM_181070] & 6.3 \\
Rab8b & RAB8B, member RAS oncogene family (Rab8b), [NM_173413] & 2.7 \\
Rae1 & RAE1 RNA export 1 homolog (S. pombe), (cDNA clone MGC:73449 IMAGE:5718934), complete & 3.3 \\
Sfrs6 & sds. [BC060072] & 2.2 \\
Sla & splicing factor, arginine/serine-rich 6 (Sfrs6), [NM_026499] & 2.7 \\
Slc31a1 & src-like adaptor (Sla), [NM_009192] & 4.2 \\
Snx11 & solute carrier family 31, member 1 (Slc31a1), [NM_175090] & 2.6 \\
Sos1 & sorting nexin 11, [AK037747] & 2.4 \\
Ssh2 & Son of sevenless homolog 1 (Drosophila) (Sos1), [NM_009231] & 4.6 \\
Stk3 & mKIAA1725 protein [AK173243] & 9.7 \\
Taf1b & serine/threonine kinase 3 (Ste20, yeast homolog) (Stk3), [NM_019635] & 4.3 \\
Vps13d & TATA box binding protein (Tbp)-associated factor, RNA polymerase I, B (Taf1b), [NM_020614] & 8.4 \\
Wdr26 & PREDICTED: Mus musculus vacuolar protein sorting 13D (yeast), transcript variant 2 (Vps13d), & 3.3 \\
Xpo4 & [XM_001002241] & 6.9 \\
\hline
\end{tabular}

Fold change: ITD-Flt $3^{+}$KLS cells derived from CreER-Survivin ${ }^{\mathrm{fx} / \mathrm{fx}}$ compared to control Survivin ${ }^{\mathrm{fx} / \mathrm{fx}}$ in two experiments.

3.3. Survivin Modulates Gene Expression in LSC That Connects Through a Functional Signaling Network Associated with Epidermal Growth Factor Receptor Signaling Pathway. Functional annotation analysis indicates that genes related with dorsoventral axis formation or epidermal growth factor receptor signaling pathway (EGFR) are significantly enriched in the shared genes associated with LSC and Survivin signaling in KEGG database (http://www.genome.jp/kegg/) $(P<.03)$. Similarly, genes associated with regulation of EGFR signaling pathway are enriched in the Gene Ontology database $(P<.02)$. Our analysis shows that 13 molecules shared by LSC and Survivin signaling are mapped on a functional signaling network that connects through the EGFR pathway (Figure 4).

\section{Discussion}

Survivin deletion in ITD-Flt3 transformed KSL cells results in a significant reduction in growth factor-independent proliferation coincident with growth inhibition. Our data shows that Survivin deletion modulates gene expression of 1,096 genes that are associated with various cellular and metabolic functions. Comparison of the 1,096 Survivin regulated genes in ITD-Flt $3^{+} \mathrm{KSL}$ cells with 3,005 differentially regulated genes in the human AML stem cell database identified 137 shared genes. Functional classification of these 137 genes indicates they connect through a functional signaling network associated with EGFR signaling pathway and affect various biological and molecular processes. Comparison of the 137 Survivin-regulated genes in LSC with transcripts regulated by Survivin in normal CD34 $4^{\text {neg }}$ KSL cells show that 124 genes are regulated by Survivin exclusively in ITDFlt $3{ }^{+}$KSL cells and not in normal HSC. These data suggest that Survivin contributes to deregulation of gene expression in AML stem cells via selective signaling pathways distinct from normal HSC that can be potentially targeted for therapeutic benefit.

There is no direct evidence that Survivin directly regulates gene transcription; however, modulation of Survivin can clearly affect transcription in cancer cells [21-23] and transgenic expression of Survivin alters the expression of multiple genes in the bladder [24].

The involvement of Survivin in transcriptional regulation is consistent with the fact that Bir1, a Caenorhabditis 
Up-regulated by survivin

(down-regulated by survivin deletion)

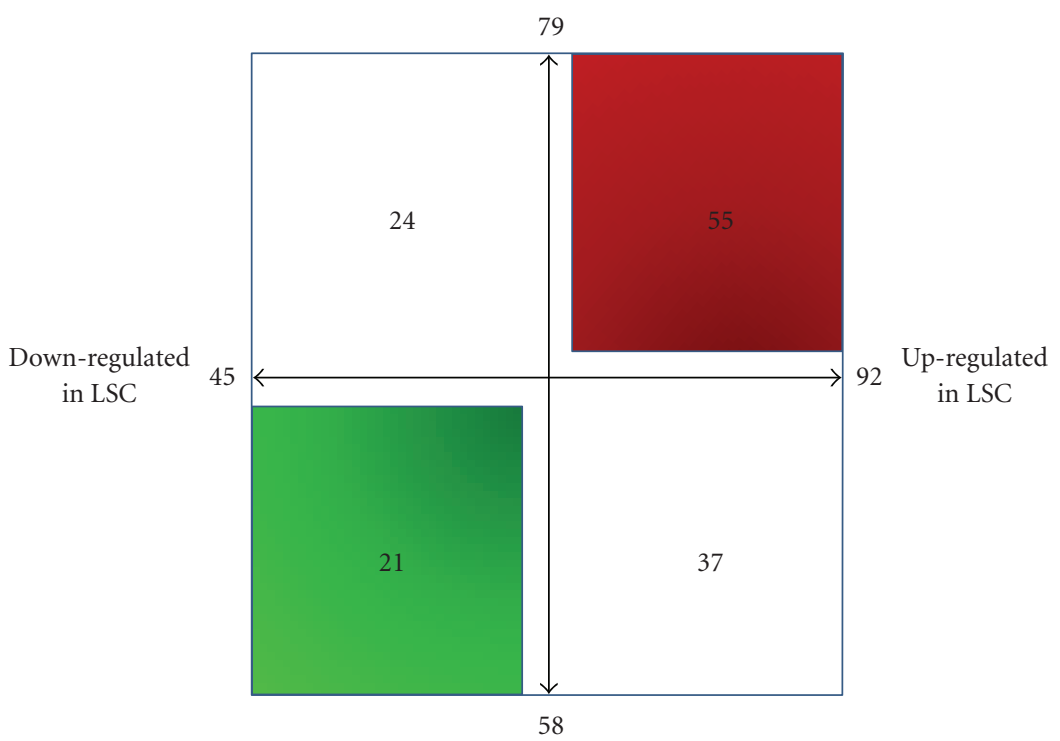

Down-regulated by survivin

(up-regulated by survivin deletion)

(a)

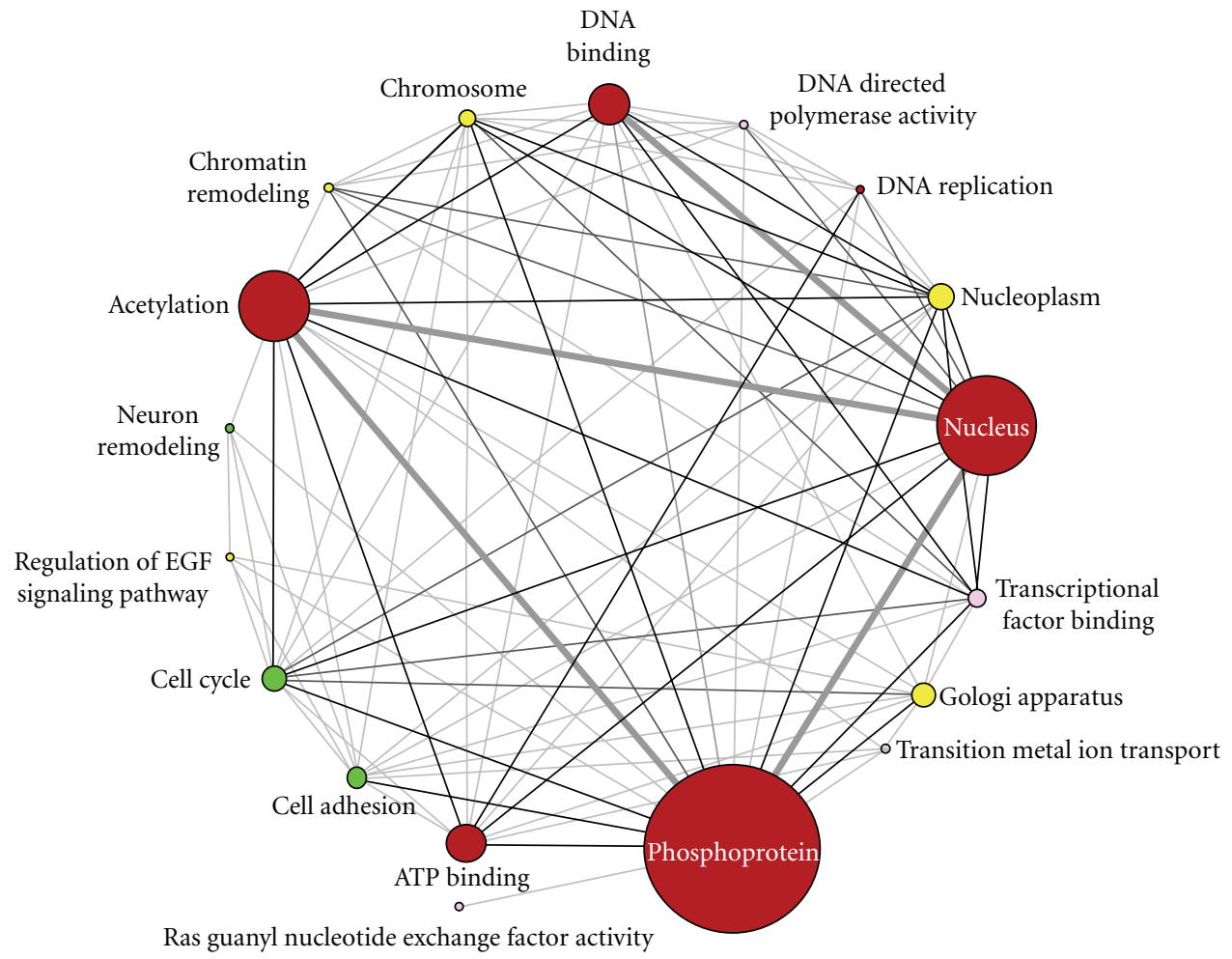

Swissprot keywords

GO biological process

GO cellular component

GO molecular function

(b)

Figure 3: Continued. 


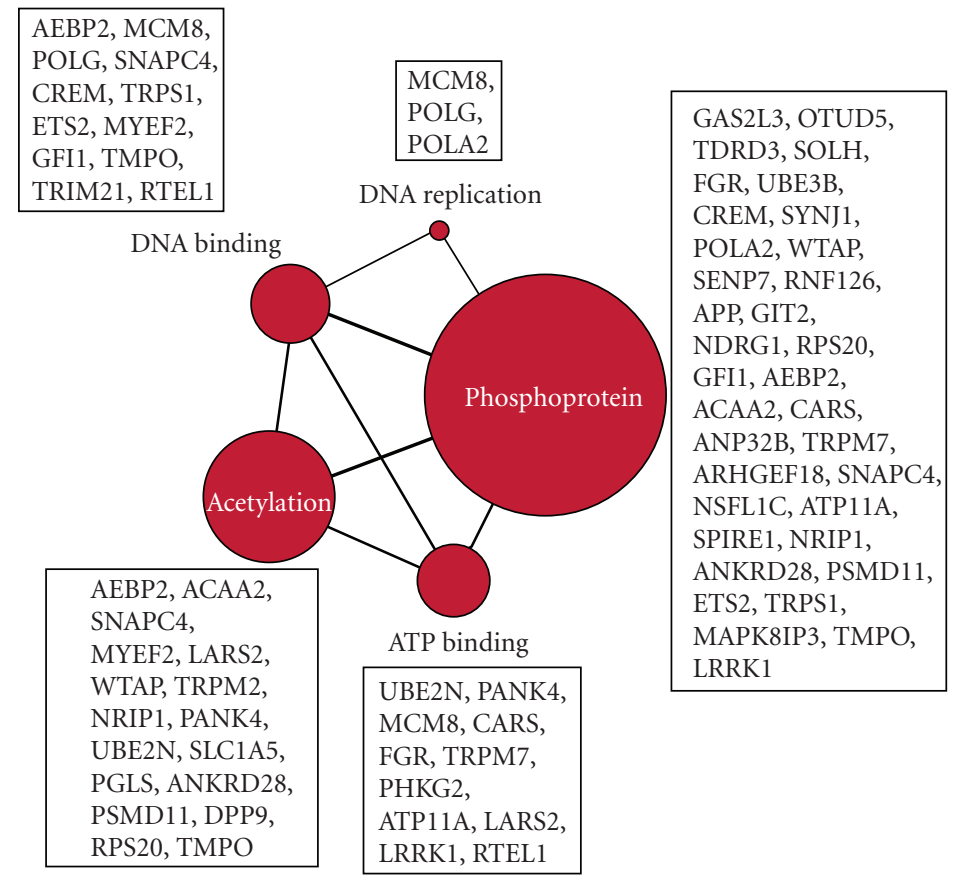

(c)

FIgURE 3: Classification of genes regulated by Survivin and LSC. (a) The 137 genes were classified based on the regulation by human LSC and Survivin in ITD-Flt $3^{+}$KSL cells. Arrow bars in the quadrant indicate the direction of gene regulation by Survivin or LSC. The topright corner shows 55 genes upregulated by both LSC and Survivin (downregulated by Survivin gene deletion), whereas bottom-left corner represents 21 genes downregulated by both LSC and Survivin (upregulated by Survivin gene deletion). The top left corner shows 24 genes downregulated by LSC but upregulated by Survivin. The bottom-right corner indicates 37 genes upregulated by LSC but downregulated by Survivin. (b) Functional group association networks for Survivin regulated genes in the list of deregulated genes in human LSC visualized using Cytoscape program. The 137 genes listed in Tables $1(\mathrm{a})-1(\mathrm{~d})$ were functionally annotated using DAVID software $(P<.05)$. The size of each circle represents the number of genes involved in each functional categories and the thickness of the line indicates the number of genes shared with any function. Functional classification was performed based on Gene Ontology Term database (biological process, molecular function and cellular component) and Swissprot Keywords. (c) The 76 genes upregulated or downregulated by Survivin and LSC (55 + 21 genes shown in Figure 3(a)) were functionally classified by DAVID software and visualized by Cytoscapse program as shown in Figure 3(b). The size of each circle represents the number of genes involved in each functional categories and the thickness of the line indicates the number of genes shared with any function. Functional classification was performed based on Swissprot Keywords. Genes annotated in each functional category are shown in the box.

elegans homologue of Survivin, regulates transcription, most likely through Histone phosphorylation by Aurora kinase [25]. Survivin is essential for activation of Aurora kinase that phosphorylates Histone $\mathrm{H} 3[26,27]$, an event required for transcriptional regulation [28-30] and cytokinesis [31], suggesting that Survivin may regulate transcription via Aurora kinase mediated Histone $\mathrm{H} 3$ phosphorylation. Over expression of Survivin also leads to phosphorylation of the Sp1 transcription factor [21]. Since microarray analysis was performed on lineage marker negative viable cells that express GFP, c-kit, and Sca-1 and survived in culture, it is unlikely that the effects of Survivin on gene expression is a consequence of KSL apoptosis, although we cannot rule out indirect effects resulting from cell cycle arrest as a consequence of Survivin deletion.

Survivin is known to inhibit caspases 3, 7, and 10 that mediate apoptosis [1-3]. Our functional annotation analysis of the genes regulated by Survivin indicates that Survivin modulates a number of genes that affect multiple biological processes and molecular functions, although inhibition of Survivin mRNA expression in CreER-Survivin ${ }^{\text {flox/flox }} \mathrm{KSL}$ cells by $4 \mathrm{OH}$-Tamoxifen was only $50 \%$ compared to control. While incompleteness of the gene deletion may affect the downstream signals, significant reduction of total cell number was observed. Since Survivin deletion induces cell death, the deleted cells are likely no longer present in the culture at the time of cell harvest for analyses, resulting in an underestimate of the efficiency of Survivin gene deletion and likely represents Survivin expression in cells that have escaped the Tamoxifen-induced deletion. The genes affected by Survivin deletion were classified into cell cycle, adhesion, DNA replication, transcriptional factor binding, acetylation, phosphorylation, and polymerase. We did not observe changes in genes that mediate apoptosis. These results suggest that Survivin can regulate ITD-Flt3 transformed KSL cell fate independent of its activity as a caspase inhibitor. More importantly, comparison of the 1,096 Survivin regulated genes in ITD-Flt $3^{+}$KLS cells with the 


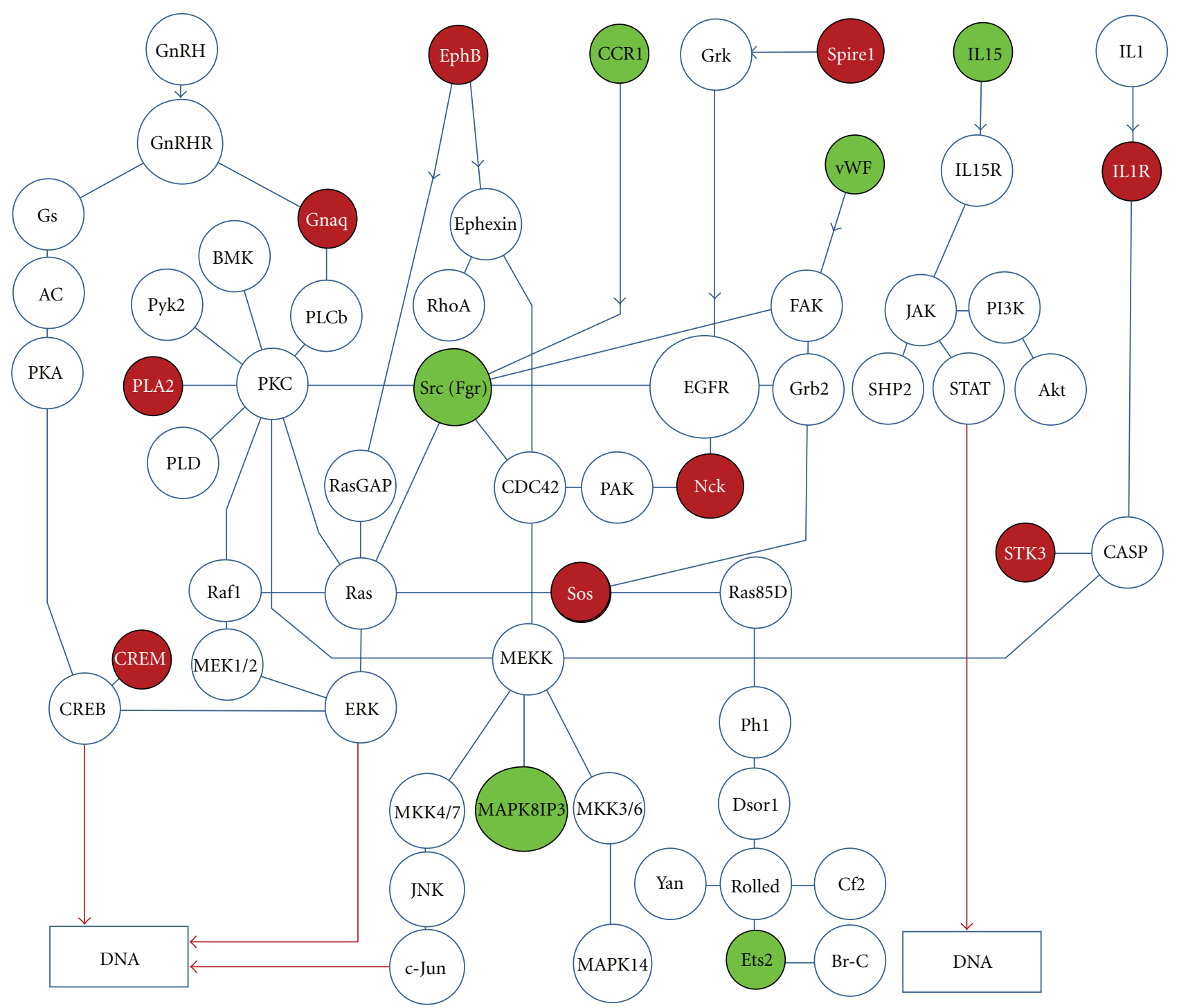

FIGURE 4: Genes regulated by Survivin in ITD-Flt ${ }^{+}$KSL cells and deregulated in LSC are mapped on functional signaling network associated with epidermal growth factor receptor signaling pathway. Epidermal growth factor receptor signaling pathway (EGFR) is significantly enriched in the shared genes associated with LSC and Survivin signaling by pathway enrichment analysis in KEGG and Gene Ontology database. Our analysis shows that 13 molecules shared by LSC and Survivin signaling are mapped on a functional signaling network associated with EGFR. The network was created based on KEGG database using Cytoscape software. Green circle and red circle represents downregulation and upregulation by Survivin gene deletion, respectively.

human AML stem cell database demonstrates that 137 genes (12.4\%) modulated by Survivin are also deregulated in LSCs. Functional annotation analysis indicates that genes related to dorsoventral axis formation or epidermal growth factor receptor signaling pathway (EGFR) are significantly enriched in the shared genes associated with LSC and Survivin signaling, even though the number of molecules detected that associates with EGFR signaling is small. EGFR signaling activates signaling cascades involved in cell proliferation, such as Src, Sos, and MAP-kinases, and is known to be dysregulated in solid tumors [32,33]. Our data also indicates that Survivin modulates expression of several genes that connect through the EGFR signaling pathway (Figure 4), suggesting a potential role of EGFR signaling downstream of Survivin in AML stem cells, despite the fact that EGFR is not usually upregulated in AML cells [34]. However, recent studies indicate an antineoplastic effect of an EGFR inhibitor in AML via off-target effects $[34,35]$. Thus, our data would support EGFR signaling as a candidate pathway for treatment of patients with AML.

While Survivin is not listed in the LSC database [16], it is expressed at higher levels in AML cells compared to normal $\mathrm{CD}_{3} 4^{+}$cells $[9,10]$. Our data clearly show that Survivin affects expression of 137 genes associated with LSC and reduces aberrant KSL proliferation induced by ITDFlt3. This finding suggests that antagonizing Survivin in LSC may normalize expression of the deregulated genes, which in turn can inhibit their aberrant proliferation. Since Survivin 
TABLE 2: Genes regulated by Survivin in ITD-Flt $3{ }^{+} \mathrm{KSL}$ cells that are preferentially expressed in HSC.

\begin{tabular}{|c|c|}
\hline symbol & dysregulation in LSC \\
\hline \multicolumn{2}{|l|}{ 2310057J16Rik } \\
\hline \multicolumn{2}{|l|}{ 2610002J02Rik } \\
\hline \multicolumn{2}{|l|}{ 2610042L04Rik } \\
\hline \multicolumn{2}{|l|}{ 4930533K18Rik } \\
\hline \multicolumn{2}{|l|}{ 9130011E15Rik } \\
\hline \multicolumn{2}{|l|}{ Adrb3 } \\
\hline \multicolumn{2}{|l|}{ Arl3 } \\
\hline \multicolumn{2}{|l|}{ Atp1b1 } \\
\hline \multicolumn{2}{|l|}{ AW112010 } \\
\hline \multicolumn{2}{|l|}{ Ccnd1 } \\
\hline \multicolumn{2}{|l|}{ Cdk9 } \\
\hline \multicolumn{2}{|l|}{ Chst1 } \\
\hline Crem & dysregulated in LSC \\
\hline \multicolumn{2}{|l|}{ Сур2e1 } \\
\hline \multicolumn{2}{|l|}{ Dnmt3b } \\
\hline Emp1 & dysregulated in LSC \\
\hline \multicolumn{2}{|l|}{ Erbb2ip } \\
\hline \multicolumn{2}{|l|}{ Fmn2 } \\
\hline \multicolumn{2}{|l|}{ Fnbp4 } \\
\hline \multicolumn{2}{|l|}{ Foxb1 } \\
\hline \multicolumn{2}{|l|}{ Gabpb1 } \\
\hline \multicolumn{2}{|l|}{ Glycam1 } \\
\hline \multicolumn{2}{|l|}{ Gpr56 } \\
\hline Hmga2 & dysregulated in LSC \\
\hline \multicolumn{2}{|l|}{ Ifi203 } \\
\hline \multicolumn{2}{|l|}{ Kcnj6 } \\
\hline \multicolumn{2}{|l|}{ Kcnmb1 } \\
\hline \multicolumn{2}{|l|}{ Lama5 } \\
\hline Lrrn 1 & dysregulated in LSC \\
\hline Ltbr & \\
\hline Maff & dysregulated in LSC \\
\hline Mup3 & \\
\hline Myef2 & dysregulated in LSC \\
\hline PCP4 & \\
\hline Prox1 & \\
\hline Rps4x & dysregulated in LSC \\
\hline Scd 2 & \\
\hline Slc22a9 & \\
\hline Slit2 & \\
\hline Sos1 & dysregulated in LSC \\
\hline Stx3 & \\
\hline Tcf3 & \\
\hline Traf1 & \\
\hline Wnt6 & \\
\hline Xrcc1 & \\
\hline
\end{tabular}

is expressed and regulated in normal $\mathrm{CD}_{3} 4^{+}$cells $[4,6]$ and antagonizing Survivin reduces normal HSPC in vivo [8], it is likely that Survivin deletion will affect normal HSC in the patients. Although direct comparison of gene expression in in vitro ITD-Flt $3^{+} \mathrm{KSL}$ cells with in vivo $\mathrm{CD} 34^{\text {neg }} \mathrm{KSL}$ cells may not necessarily provide definite differences in Survivin signaling between these populations in vivo, we found that 124 out of 137 Survivin associated genes shared by ITD-Flt $3{ }^{+} \mathrm{KSL}$ cells and human LSC were not regulated in normal CD34 ${ }^{\text {neg }}$ KSL cells by Survivin. This disparity of downstream signaling of Survivin between normal and transformed HSC may represent as a means of identifying novel therapeutic targets against LSC that would thereby supplant direct Survivin disruption which would otherwise toxic to normal HSC.

\section{Conclusion}

We identified genes regulated by Survivin in ITD-Flt3 transformed KSL cells that are deregulated in human AML stem cells that are distinct from normal HSC. This study will facilitate the identification of specific therapeutic targets downstream of Survivin to eradicate LSC without affecting normal HSC.

\section{Acknowledgments}

The authors thank Susan Rice and Denessa Lucket for cell sorting. Supported by Biomedical Research Grant from Indiana University School of Medicine, Research Support Funds Grant from Indiana University, Purdue University, Indianapolis, Research Support Funds from Mochida Memorial Foundation for Medical and Pharmaceutical Research, Sankyo Biomedical Research Foundation and Mitsubishi Pharma Research Foundation, Japan Leukaemia Research Fund, AstraZeneca Research Grant, Grant-in-Aid for Scientific Research (B) (20390298) from Japan Society for the Promotion of Science (to SF) and US Public Health Service grants (HL69669, HL079654, and HL096305) from the National Institutes of Health (to LMP). EMC is an adjunct scientist with the Canadian Blood Services, holds a Canada Research Chair in Endothelial Biology and a CSL-Behring Research Chair. The authors disclose no conflict of interest associated with this work. Human subjects are not involved.

\section{References}

[1] D. C. Altieri, "Survivin, versatile modulation of cell division and apoptosis in cancer," Oncogene, vol. 22, no. 53, pp. 85818589, 2003.

[2] D. C. Altieri, "Validating survivin as a cancer therapeutic target," Nature Reviews Cancer, vol. 3, no. 1, pp. 46-54, 2003.

[3] S. Fukuda and L. M. Pelus, "Survivin, a cancer target with an emerging role in normal adult tissues," Molecular Cancer Therapeutics, vol. 5, no. 5, pp. 1087-1098, 2006.

[4] S. Fukuda, R. G. Foster, S. B. Porter, and L. M. Pelus, "The antiapoptosis protein survivin is associated with cell cycle entry of normal cord blood CD $34^{+}$cells and modulates cell cycle and proliferation of mouse hematopoietic progenitor cells," Blood, vol. 100, no. 7, pp. 2463-2471, 2002.

[5] S. Fukuda and L. M. Pelus, "Elevation of Survivin levels by hematopoietic growth factors occurs in quiescent CD34+ hematopoietic stem and progenitor cells before cell cycle entry," Cell Cycle, vol. 1, no. 5, pp. 322-326, 2002. 
[6] S. Fukuda and L. M. Pelus, "Regulation of the inhibitor-ofapoptosis family member survivin in normal cord blood and bone marrow $\mathrm{CD} 34^{+}$cells by hematopoietic growth factors: implication of survivin expression in normal hematopoiesis," Blood, vol. 98, no. 7, pp. 2091-2100, 2001.

[7] S. Fukuda, C. R. Mantel, and L. M. Pelus, "Survivin regulates hematopoietic progenitor cell proliferation through p21WAF1/Cip1-dependent and-independent pathways," Blood, vol. 103, no. 1, pp. 120-127, 2004.

[8] C. G. Leung, Y. Xu, B. Mularski, H. Liu, S. Gurbuxani, and J. D. Crispino, "Requirements for survivin in terminal differentiation of erythroid cells and maintenance of hematopoietic stem and progenitor cells," Journal of Experimental Medicine, vol. 204, no. 7, pp. 1603-1611, 2007.

[9] B. Z. Carter, M. Milella, D. C. Altieri, and M. Andreeff, "Cytokine-regulated expression of survivin in myeloid leukemia," Blood, vol. 97, no. 9, pp. 2784-2790, 2001.

[10] C. Adida, C. Recher, E. Raffoux et al., "Expression and prognostic significance of survivin in de novo acute myeloid leukaemia," British Journal of Haematology, vol. 111, no. 1, pp. 196-203, 2000.

[11] A. Badran, A. Yoshida, Y. Wano et al., "Expression of the anti-apoptotic gene survivin in myelodysplastic syndrome," International Journal of Oncology, vol. 22, no. 1, pp. 59-64, 2003.

[12] D. G. Gilliland and J. D. Griffin, "The roles of FLT3 in hematopoiesis and leukemia," Blood, vol. 100, no. 5, pp. 15321542, 2002.

[13] M. Levis, K. M. Murphy, R. Pham et al., "Internal tandem duplications of the FLT3 gene are present in leukemia stem cells," Blood, vol. 106, no. 2, pp. 673-680, 2005.

[14] S. Fukuda, P. Singh, A. Moh et al., "Survivin mediates aberrant hematopoietic progenitor cell proliferation and acute leukemia in mice induced by internal tandem duplication of Flt3," Blood, vol. 114, no. 2, pp. 394-403, 2009.

[15] V. E. Velculescu, S. L. Madden, L. Zhang et al., "Analysis of human transcriptomes," Nature Genetics, vol. 23, no. 4, pp. 387-388, 1999.

[16] R. Majeti, M. W. Becker, Q. Tian et al., "Dysregulated gene expression networks in human acute myelogenous leukemia stem cells," Proceedings of the National Academy of Sciences of the United States of America, vol. 106, no. 9, pp. 3396-3401, 2009.

[17] L. M. Kelly, Q. Liu, J. L. Kutok, I. R. Williams, C. L. Boulton, and D. G. Gilliland, "FLT3 internal tandem duplication mutations associated with human acute myeloid leukemias induce myeloproliferative disease in a murine bone marrow transplant model," Blood, vol. 99, no. 1, pp. 310-318, 2002.

[18] D. W. Huang, B. T. Sherman, and R. A. Lempicki, "Systematic and integrative analysis of large gene lists using DAVID bioinformatics resources," Nature Protocols, vol. 4, no. 1, pp. 44-57, 2009.

[19] M. S. Cline, M. Smoot, E. Cerami et al., "Integration of biological networks and gene expression data using Cytoscape," Nature Protocols, vol. 2, no. 10, pp. 2366-2382, 2007.

[20] N. B. Ivanova, J. T. Dimos, C. Schaniel, J. A. Hackney, K. A. Moore, and I. R. Lemischka, "A stem cell molecutar signature," Science, vol. 298, no. 5593, pp. 601-604, 2002.

[21] K. Asanuma, N. Tsuji, T. Endoh, A. Yagihashi, and N. Watanabe, "Survivin enhances fas ligand expression via upregulation of specificity protein 1-mediated gene transcription in colon cancer cells," The Journal of Immunology, vol. 172, no. 6, pp. 3922-3929, 2004.
[22] B. T. Takizawa, E. M. Uchio, J. J. Cohen, M. A. Wheeler, and R. M. Weiss, "Downregulation of survivin is associated with reductions in TNF receptors' mRNA and protein and alterations in nuclear factor kappa B signaling in urothelial cancer cells," Cancer Investigation, vol. 25, no. 8, pp. 678-684, 2007.

[23] M. Y. Balkhi, M. Christopeit, Y. Chen, M. Geletu, and G. Behre, "AML1/ETO-induced survivin expression inhibits transcriptional regulation of myeloid differentiation," Experimental hematology, vol. 36, no. 11, pp. 1449-1460, 2008.

[24] W. Salz, D. Eisenberg, J. Plescia et al., "A survivin gene signature predicts aggressive tumor behavior," Cancer Research, vol. 65, no. 9, pp. 3531-3534, 2005.

[25] M. Kostrouchova, Z. Kostrouch, V. Saudek, J. Piatigorsky, and J. E. Rall, "BIR-1, a Caenorhabditis elegans homologue of Survivin, regulates transcription and development," Proceedings of the National Academy of Sciences of the United States of America, vol. 100, no. 9, pp. 5240-5245, 2003.

[26] J. Chen, S. Jin, S. K. Tahir et al., "Survivin enhances auroraB kinase activity and localizes aurora-B in human cells," The Journal of Biological Chemistry, vol. 278, no. 1, pp. 486-490, 2003.

[27] M. A. Bolton, W. Lan, S. E. Powers, M. L. McCleland, J. Kuang, and P. T. Stukenberg, "Aurora B kinase exists in a complex with survivin and INCENP and its kinase activity is stimulated by survivin binding and phosphorylation," Molecular Biology of the Cell, vol. 13, no. 9, pp. 3064-3077, 2002.

[28] S. J. Nowak and V. G. Corces, "Phosphorylation of histone H3 correlates with transcriptionally active loci," Genes and Development, vol. 14, no. 23, pp. 3003-3013, 2000.

[29] J. Li, Q. Lin, H.-G. Yoon et al., "Involvement of histone methylation and phosphorylation in regulation of transcription by thyroid hormone receptor," Molecular and Cellular Biology, vol. 22, no. 16, pp. 5688-5697, 2002.

[30] P. Cheung, K. G. Tanner, W. L. Cheung, P. Sassone-Corsi, J. M. Denu, and C. D. Allis, "Synergistic coupling of histone $\mathrm{H} 3$ phosphorylation and acetylation in response to epidermal growth factor stimulation," Molecular Cell, vol. 5, no. 6, pp. 905-915, 2000.

[31] Y. Wei, L. Yu, J. Bowen, M. A. Gorovsky, and C. David Allis, "Phosphorylation of histone $\mathrm{H} 3$ is required for proper chromosome condensation and segregation," Cell, vol. 97, no. 1, pp. 99-109, 1999.

[32] R. H. Alvarez, V. Valero, and G. N. Hortobagyi, "Emerging targeted therapies for breast cancer," Journal of Clinical Oncology, vol. 28, no. 20, pp. 3366-3379, 2010.

[33] T. J.R. Harris and F. McCormick, "The molecular pathology of cancer," Nature Reviews Clinical Oncology, vol. 7, no. 5, pp. 251-265, 2010.

[34] C. K. Hahn, J. E. Berchuck, K. N. Ross et al., "Proteomic and genetic approaches identify Syk as an AML target," Cancer Cell, vol. 16, no. 4, pp. 281-294, 2009.

[35] S. Boehrer, L. Adès, T. Braun et al., "Erlotinib exhibits antineoplastic off-target effects in AML and MDS: a preclinical study," Blood, vol. 111, no. 4, pp. 2170-2180, 2008. 


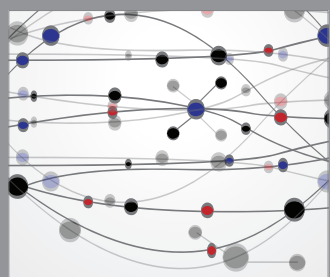

The Scientific World Journal
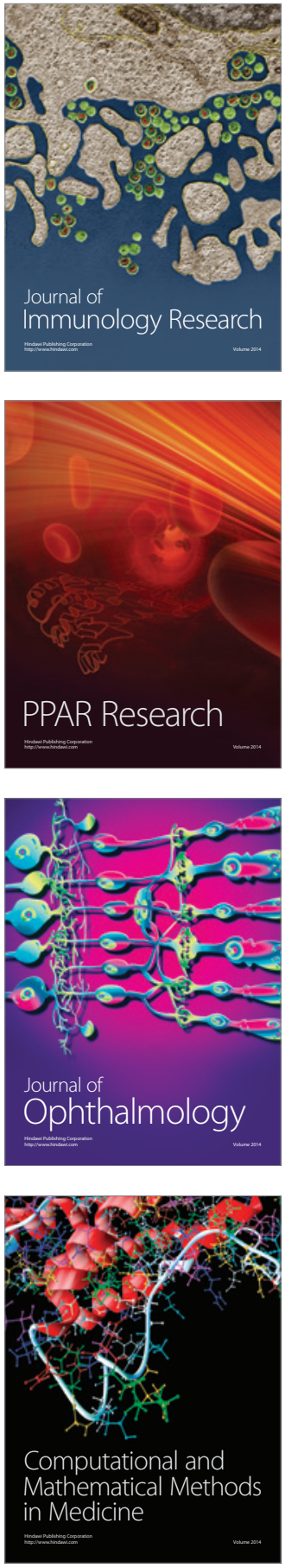

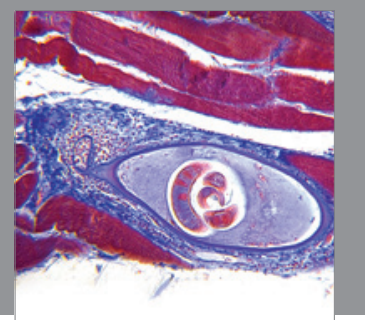

Gastroenterology

Research and Practice
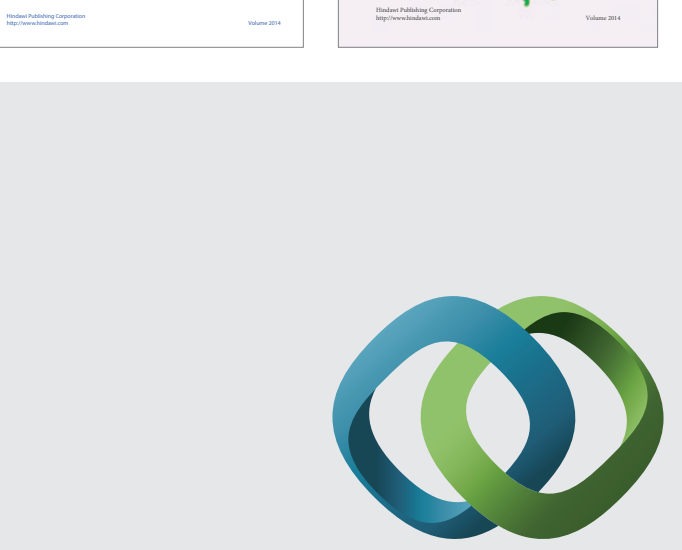

\section{Hindawi}

Submit your manuscripts at

http://www.hindawi.com
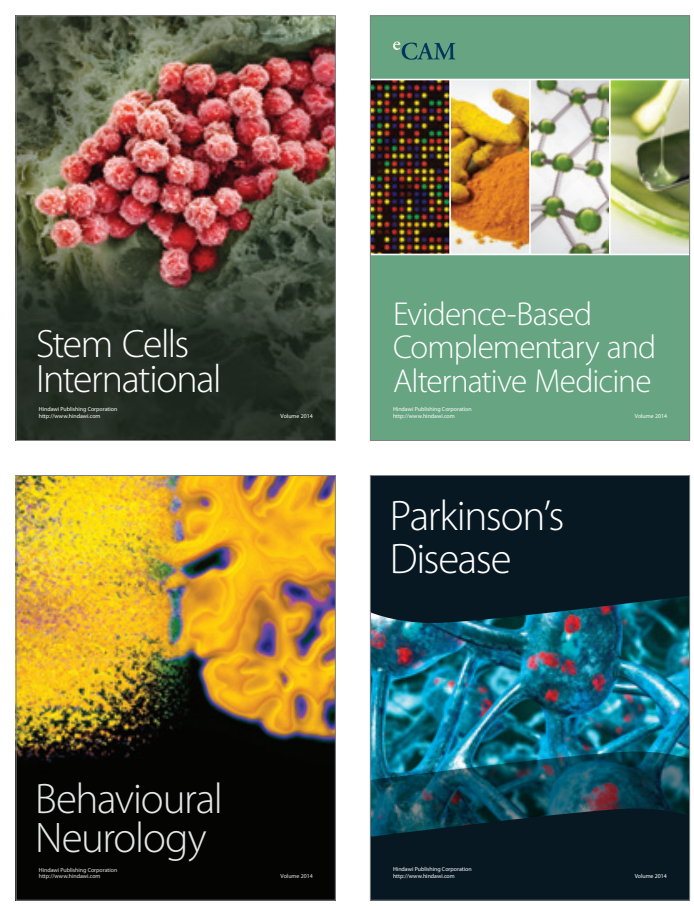

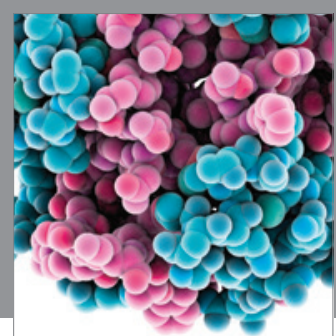

Journal of
Diabetes Research

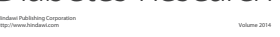

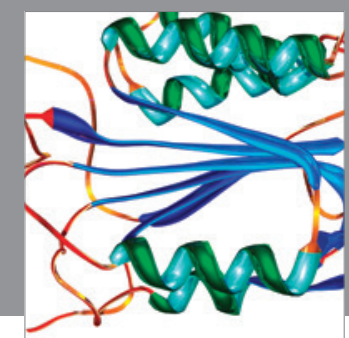

Disease Markers
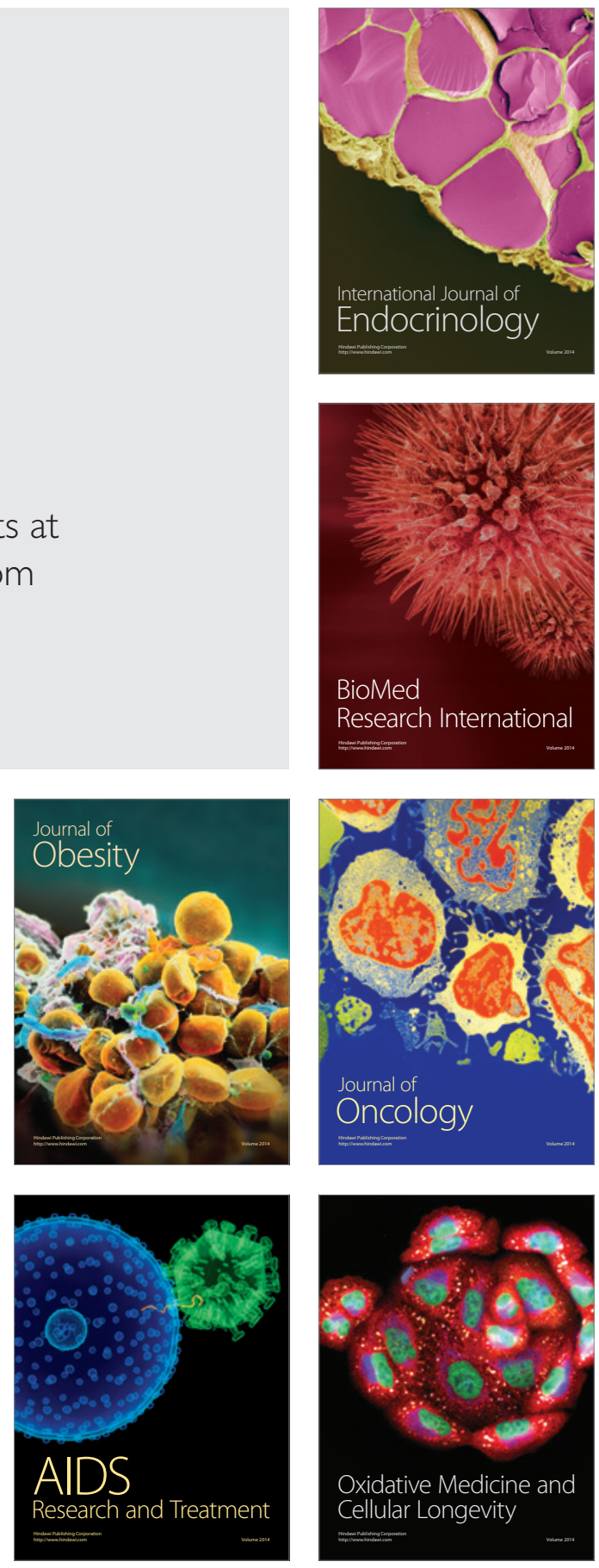